\title{
Educational Planning for Elderly People
}

ISSN: 2578-0093

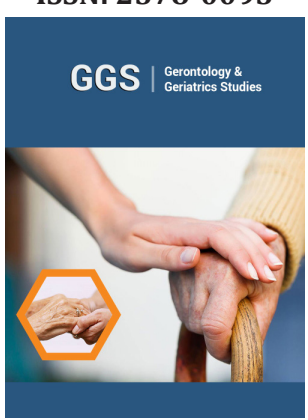

*Corresponding author: Öztop $\mathrm{H}$, Family and Consumer Sciences, Hacettepe University, Turkey

Submission: 酩 October 18, 2019

Published: 温November 27, 2019

Volume 5 - Issue 3

How to cite this article: Öztop $\mathrm{H}$ Pekmezci P. Educational Planning for Elderly People. Gerontol \& Geriatric stud.5(3). GGS.000615.2019.

DOI: 10.31031/GGS.2019.05.000615

Copyright@ Öztop H, This article is distributed under the terms of the Creative Commons Attribution 4.0 International License, which permits unrestricted use and redistribution provided that the original author and source are credited.

\author{
Öztop $H^{*}$ and Pekmezci P \\ Family and Consumer Sciences, Hacettepe University, Turkey
}

\begin{abstract}
Technology, medical development and increased awareness of maintaining health have extended life expectancies, thereby increasing the elderly population. This increase has resulted in the need for further studies and policies on elderly people, including studies into educational planning for elderly people. In order to ensure an active and successful ageing process, it is therefore important to plan educational programs for the elderly by adopting a common approach, one that is in line with health, sheltering, disability, and social-welfare policies and prioritize the needs of elderly people.
\end{abstract}

Keywords: Elderly education; Adult education; Successful ageing process

\section{Mini Review}

It is important to benefit from education-based practices to ensure that elderly people live more active lives, carry out self-care independently, and are more satisfied with their lives [1]. Educational activities may constitute a substantial part of elderly people's daily lives [2] while also contributing to their welfare. In addition, adult education for elderly people plays an important role in improving the abilities and motivation of affected individuals so that they can more effectively maintain connections with social life, cope with daily life problems, and participate in society as autonomous and social individuals. Supporting

an active ageing process means realizing learning requirements in old age, creating opportunities to meet these requirements, and ensuring the continuity of the education programs, because learning is equivalent to being productive [3]. However, elderly people are usually unable to access education due to certain reasons, including a lack of elderly educational institutions, a lack of self-confidence among elderly people, and low motivation toward education etc. [2].

Recently studies on elderly education have become more common and have resulted in discussions as to whether elderly education should be evaluated separately from adult education. Some educators indicate that elderly education should be evaluated as a separate category, while others state that such a separation would oppose the content of adult education, and therefore, they should be evaluated together [4]. On the other hand, studies on elderly education generally address determining educational needs and providing recommendations to policymakers. Additionally, education provided to elderly people generally concern health issues [5-10]. However, another important issue in this field is to determine the reasons pertaining to the educational needs of individuals after retirement, as well as the means used to facilitate learning; this will ensure the improvement of educational activities by obtaining more reliable information about the content, process, and method concerned [4]. Legalization of educational services toward elderly people and the allocation public-expenditure resources for education are of primary importance too fast and successful education-planning process. Therefore, a common approach that is in line with health, sheltering, disability, and socialwelfare policies and considers the needs and characteristics of elderly people should be adopted during the development of a lifelong learning policy. The following subjects should therefore be considered during the planning of elderly education:

a) Differences between the age groups should be considered to achieve successful learning environments; and the needs of elderly people should be detected and evaluated during the preparation of education programs. 
b) The interests, abilities, desires, experiences, needs, and motivation of elderly people should be determined by providing various options.

c) Elderly people both need and want to be active in sharing experiences and making decisions. It is therefore critical to listen to and understand elderly people, as well as to benefit from their knowledge and experience. Educators should involve elderly people in every stage of the educational process.

d) Studying skills, memory techniques, and learning approaches that participants can use in various ways should be improved. Answering questions should be encouraged during education and positive feedback should be provided to develop elderly people's sense of competence [11-13].

e) The education provided should aim to strengthen elderly people's ability to look after themselves and should support their adoption of the principle of lifelong learning. Accordingly, education programs that support active ageing and appeal to the elderly people will be conducted using entertaining methods throughout the learning and educating process.

f) Both formal and informal entities should exclusively support the provision of education for elderly people and ensuring the validation of education. Continuous education should be adopted as a citizenship objective.

g) The process-rather than the results-of education should be considered. Moreover, the focus should be on subject-oriented models that accept the eagerness of the elderly regarding their education, as well as on educational objectives.

h) Education programs should be prepared in a way that facilitates elderly people's developmental periods and transition to developmental tasks; in particular, they should help participants cope with the difficulties arising from developmental tasks. All these acquisitions will keep the cognitive functions-such as obtaining information and memorizing-active, as these are used during education. i) Involving elderly people in all stages of an educational program's development and management-which are determination of the educational needs, planning, implementation, and evaluationwill make a significant contribution to the progress of the subject.

\section{References}

1. Sin MK, Belza B, Logerfo J, Cunningham S (2005) Evaluation of a community-based exercise program for elderly Korean immigrants. Public Health Nurs 22(5): 407-413.

2. Friebe J, Hertha BS (2013) Activities and barriers to education for elderly people. Journal of Contemporary Educational Studies 1: 10-26.

3. Ünalan PC (2012) Active ageing: cognitive and social aspect. The Journal of Turkish Family Physician 3(1): 13-17.

4. Glendenning F (2001) Education for older adults. International Journal of Lifelong Education 20(1-2): 63-70.

5. Chapman KM, Ham JO, Liesen P, Winter L (1995) Applying behavioral models to dietary education of elderly diabetic patients. Journal of Nutrition Education 27(2): 75-79.

6. Gomez DR (2016) Critical Geragogy and foreign language learning: An exploratory application. Educational Gerontology 42(2): 136-143.

7. Gülsoy H (2017) The effect of self-care education on health promotion of elderly. Institute of Health Sciences, Haliç University, Istanbul, Turkey.

8. Akgül H, Yeşilyaprak B (2018) The effect of psychoeducation program for reducing loneliness level of the elderly. International Journal of Society Research 8(14): 11-52.

9. Eren D (2018) The effect of an education program for supporting healthiness on elderly people's quality of life, sense of coherence, and resilience. Institute of Health Sciences, Ege University, Izmir, Turkey.

10. Akkurt SS, Öztop H (2019) A study for determining the educational needs of older adults for a successful aging. International Forum of Neurosciences, p. 58 .

11. Lewis GMB (2010) Education and learning for the elderly: why, how, what. Educational Gerontology 36(3): 213-228.

12. National Research Council (2001) Preparing for an aging world: The case for cross national research. Panel on a Research Agenda and New Data for an Aging World. Washington DC: National Academy Press.

13. WHO (1989)" Health of the elderly: Report of a WHO expert committee ["meeting held in Geneva from 3 to 9 November 1987]. World Health Organization. 